\title{
Electron-Microscopic Studies on the Palatine Tonsil of the Buffalo (Bubalus bubalis)
}

\author{
Ibrahim Alhaji Girgiri and Pawan Kumar
}

\author{
Department of Veterinary Anatomy, College of Veterinary Sciences, Lala Lajpat Rai University of Veterinary \\ and Animal Sciences, Hisar-125 004, India
}

\begin{abstract}
The study examined the ultrastructural features of the palatine tonsils of the local mixed breed of adult buffaloes using scanning and transmission electron microscopy. The tissue samples collected from the palatine tonsils were fixed in $2 \%$ glutaraldehyde solution and processed for scanning and transmission electron microscopy. The scanning electron microscopy of the tonsil's surface epithelium presented folded mucosa consisting of folds divided by shallow grooves. The mucosal surface was having a squamous arrangement of cells that were delineated from the adjacent cells. These cells at higher magnification presented the microplicae, which appeared as if filled with material. A few small duct openings were irregularly placed throughout the mucosal surface. The transmission electron-microscopy elaborated structural details of the distinct strata of the surface and reticular epithelia, the cell organelles as well as the lymphocytes migration across the high endothelial venules. The vesiculo-vacuolar organelle was also observed. The study provided detailed ultramicroscopic features of the palatine tonsil, which might play a significant role in the induction of immunity against ingested antigens sampled at the mucosal surface.
\end{abstract}

Keywords: Ultrastructure, Microplicae, Vesiculo-Vacuolar Organelle, High Endothelial Venules, Buffaloes.

\section{INTRODUCTION}

The palatine tonsil, a major component of Waldeyer's ring of lymphoid tissue, is well positioned along the digestive tract providing a defensive barrier against ingested antigens [1]. The location plays a critical immune inductive role for the tonsil, which participates as an effector organ of the local and mucosal adaptive immune responses [2]. The specialised tonsil structures which contribute to immune functions consist of the reticular crypt epithelium, which acts as an inductive site where antigens sampled from the mucosal surface are translocated to underlying lymphoid cells [3] and the subepithelial lymphoid compartments consisting of germinal centres in B-cell follicles, surrounded by T-cell rich zones, abundant plasma cells, and a variety of antigen-presenting cells (APCs) comparable to lymph nodes, but not truly encapsulated and lacked afferent lymphatics [4]. Systemic migration of these lymphoid cells into inductive lymphoid compartments takes place through the high endothelial post-capillary venules (HEVs) $[5,6]$ regulated by several adhesion molecules and chemokine receptors [7]. The ultrastructural features of palatine tonsils have been earlier described in the horse [5], camel [8], and bovine [9]. The transmission electron microscopic features of palatine tonsil have been described in Egyptian buffalo (Bos Bubalus) [10]. The tonsils of the nasopharyngeal region of the buffalo have been studied in detail $[11,12]$. The

*Address correspondence to this author at the Department of Veterinary Anatomy, College of Veterinary Sciences, Lala Lajpat Rai University of Veterinary and Animal Sciences, Hisar-125 004, India; Tel: +919466402637; E-mail: pkumar@luvas.edu.in; pawanrajoria2000@rediffmail.com present study aimed to investigate the ultrastructural details of the buffalo's palatine tonsil, emphasising the distribution of reticular epithelium, lymphoid tissue, and associated structures that may be of use to microbiologists to understand and explore the early pathogenesis of diseases like Hemorrhagic septicemia in buffaloes.

\section{MATERIALS AND METHODS}

\section{Scanning Electron Microscopy}

Fresh tissues of palatine tonsils of both sides were collected from 6 heads of clinically healthy adult buffaloes (Bubalus bubalis) of 5-6 years of age of local mixed breed irrespective of sex were procured from Municipal Slaughterhouse Ghazipur, New Delhi, India after their sacrifice by captive bolt stunning gun method. The tissues were washed twice in chilled $0.1 \mathrm{M}$ phosphate buffer $(\mathrm{pH} \quad 7.4)$ and fixed with $2 \%$ glutaraldehyde solution in $0.1 \mathrm{M}$ phosphate buffer $(\mathrm{pH}$ 7.4) for 6-8 hours. The tissues were rewashed twice with $0.1 \mathrm{M}$ phosphate buffer, and the rest of the procedure was carried out at EM Lab., A.I.R.F., J.N.U. and A.I.I.M.S., New Delhi. The tissues were dehydrated using ascending grades of alcohol, critical point dried, mounted on stubs and sputter-coated with gold. The tissues were viewed using a scanning electron microscope ((Zeiss EVO-40, New York, USA) at EM Labs., New Delhi.

\section{Transmission Electron Microscopy}

The palatine tonsils collected for scanning electron microscopy were washed with $0.1 \mathrm{M}$ phosphate buffer, 
and the tissues of $1 \mathrm{~mm}^{2}$ were primarily fixed with $2.5 \%$ glutaraldehyde solution in $0.1 \mathrm{M}$ phosphate buffer $(\mathrm{pH}$ 7.4) for 6-8 hours followed by post-fixation in $2 \%$ osmium tetraoxide for 1 hour. The rest of processing to prepare resin blocks were carried out at EM Lab., A.I.I.M.S., New Delhi. Thin sections of $1 \mu$ were stained with toluidine blue to select the most appropriate area of the tissues. The ultrathin sections $(50-70 \mathrm{~nm})$ were taken on copper grids, stained with lead citrate and uranyl acetate. The processed tissues were viewed under a transmission electron microscope (Technai G2, SEI Co., Netherland) to record areas of interest for observations and photographs at EM Lab., A.I.I.M.S., New Delhi.

\section{RESULTS}

\section{Scanning Electron Microscopy}

The palatine tonsil presented a folded mucosa with a few main longitudinal folds, which further showed transversely oriented grooves and folds of varying shapes and sizes (Figures 1, 2). Some of the folds were extending throughout the width of these longitudinal folds, whereas some other folds reached only up to half of these longitudinal folds. These grooves and folds were like the small narrow crests. The large-sized, oval or crescent-shaped crypts were distinctly visible (Figures 1,3 ). These crypts were also surrounded by the folded mucosa, which presented the transversely oriented smaller folds (Figure 3 ). The surface of the palatine tonsil presented the continuous sheet of cells, which were of irregular shapes and size and were continuous with each other, and at places, desquamating cells were also observed. The further

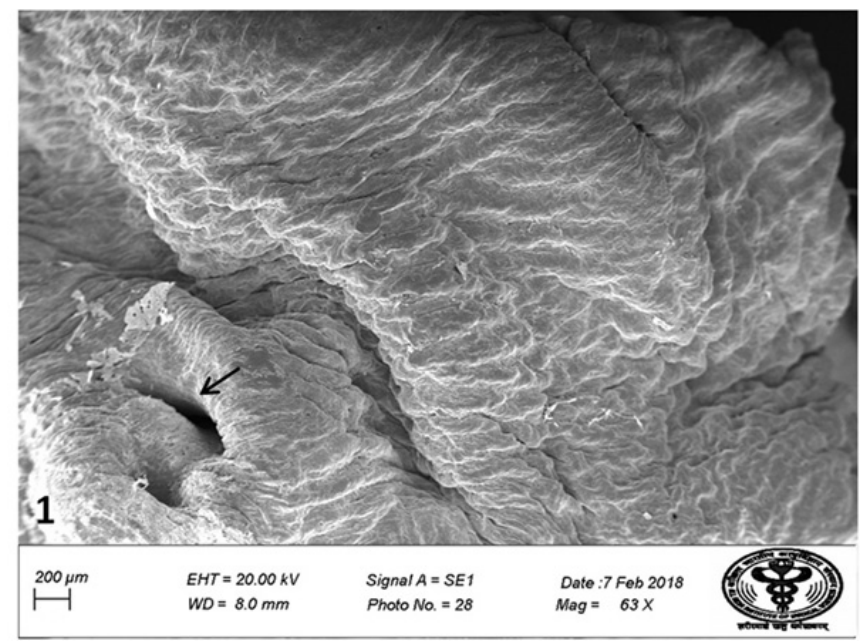

Figure 1: Scanning electron-micrograph of palatine tonsil of buffalo showing folds, and distinctly large-sized crypts (arrow). x 63; (bar $200 \mu \mathrm{m})$. magnification of these cells presented the microplicae of varying patterns. These were appearing as if filled

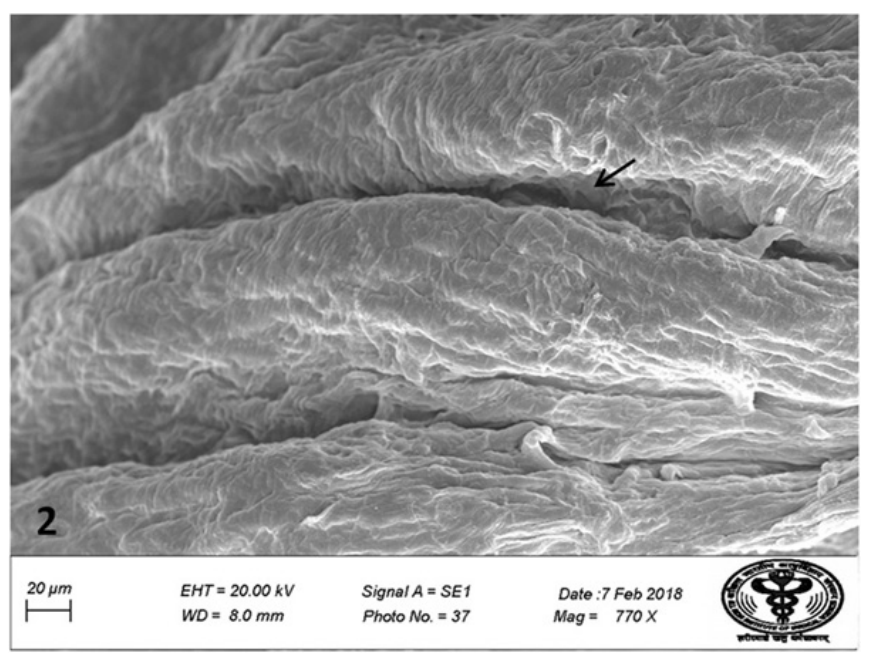

Figure 2: Scanning electron-micrograph of palatine tonsil of buffalo showing longitudinal folds and transversely oriented grooves (arrow). x 770; (bar $20 \mu \mathrm{m})$.

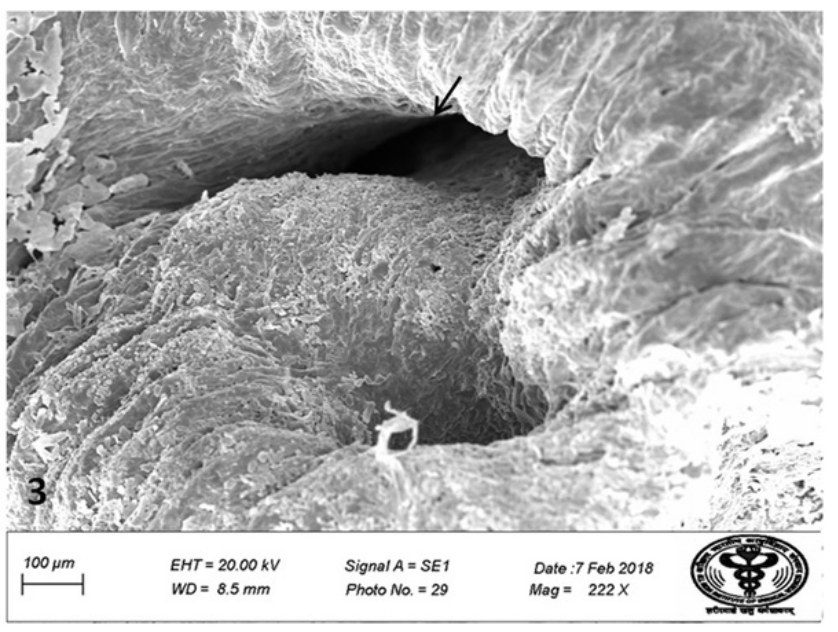

Figure 3: Scanning electron-micrograph showing oval or crescent-shaped openings of the crypts (arrow). x 222; (bar $100 \mu \mathrm{m})$.

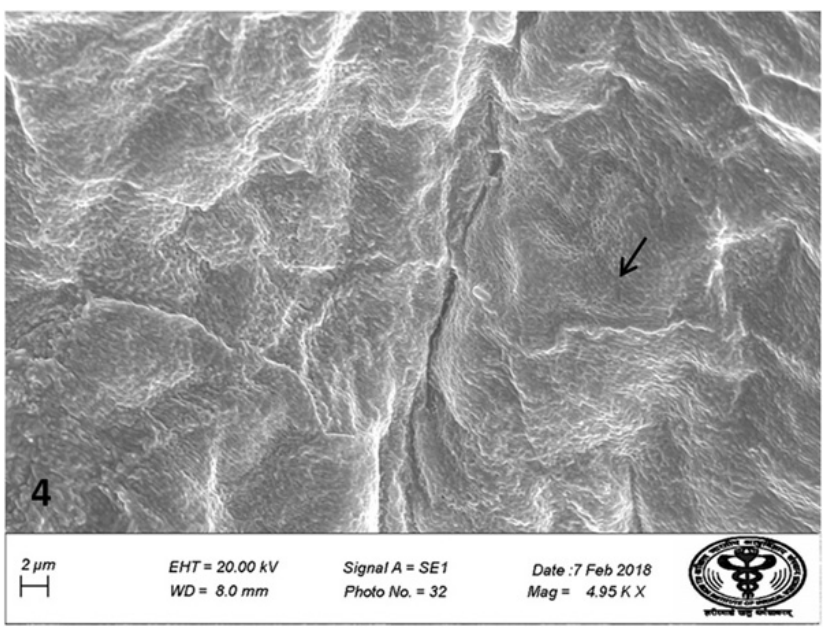

Figure 4: Scanning electron-micrograph showing squamous surface cells having microplicae (arrow). x 4950; (bar $2 \mu \mathrm{m})$. 
with some material. Thus, the spaces between the microplicae were drastically reduced (Figures 4, 5).

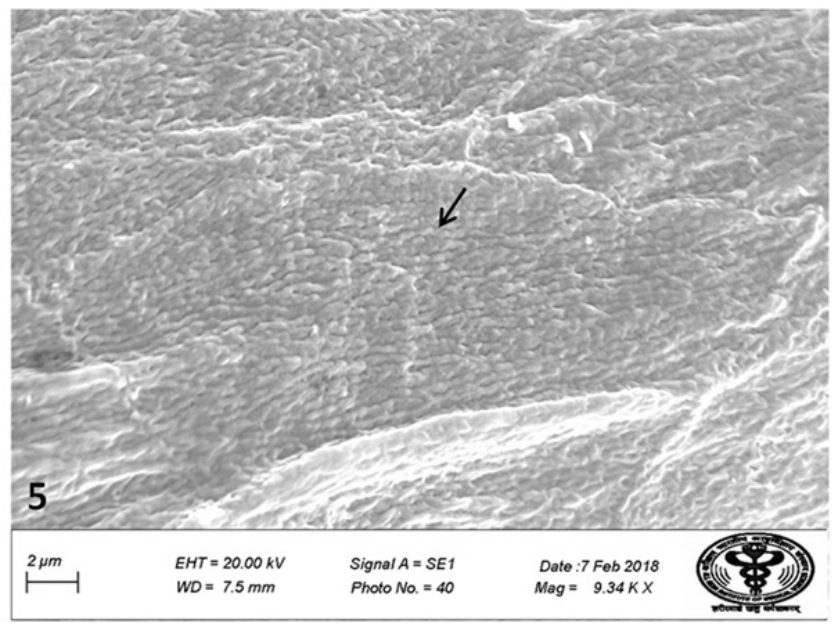

Figure 5: Scanning electron-micrograph at higher magnification, showing microplicae of varying shapes and size (arrow). x 9340; (bar $2 \mu \mathrm{m})$.

Small ducts openings observed in between the cells of the surface of the palatine tonsil presented narrow lumen-like structure being obliterated because of the presence of the projection of the cells or secretions of the gland. The duct's cell lining did not present microplicae, it presented an irregular surface with small projections like microvilli. The cut surface of the palatine tonsil presented distinctly visible crypts being lined by a folded group of cells, and the surface of these cells was surrounded by a very fine droplet of the secretion (Figure 6). The inner surface presented the microplicae like the arrangement, which were generally like the bacteria colonies (Figure 7). The cut surface also revealed the lymphoid tissue's presence, showing

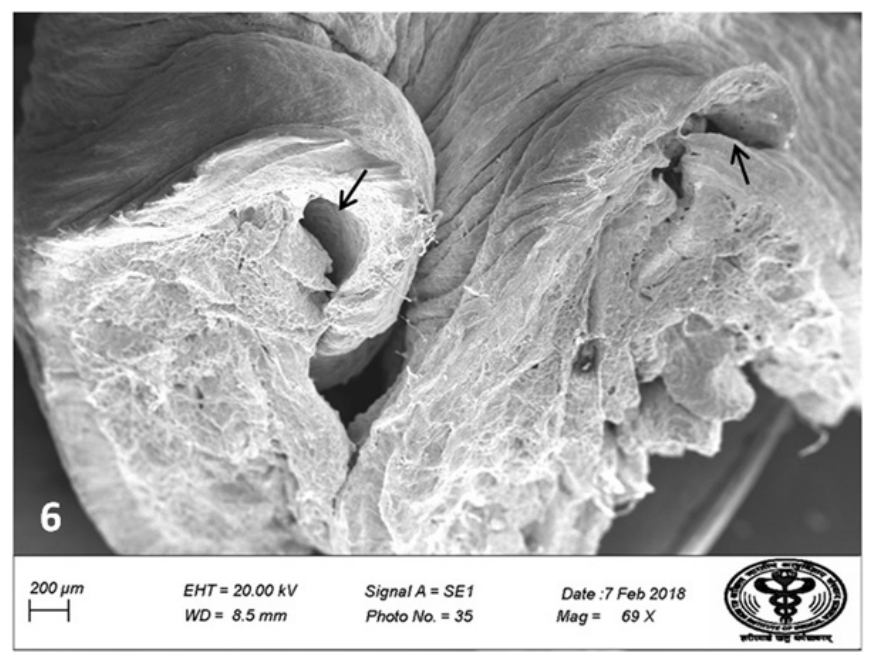

Figure 6: Scanning electron micrograph showing the cut surface of the PT with distinctly visible crypts (arrow). x 69; (bar $200 \mu \mathrm{m}$ ). the presence of lymphocytes and the lymphoid follicles (Figure 8). These lymphocytes were also of varying shapes and size and were generally present in an overlapping pattern.

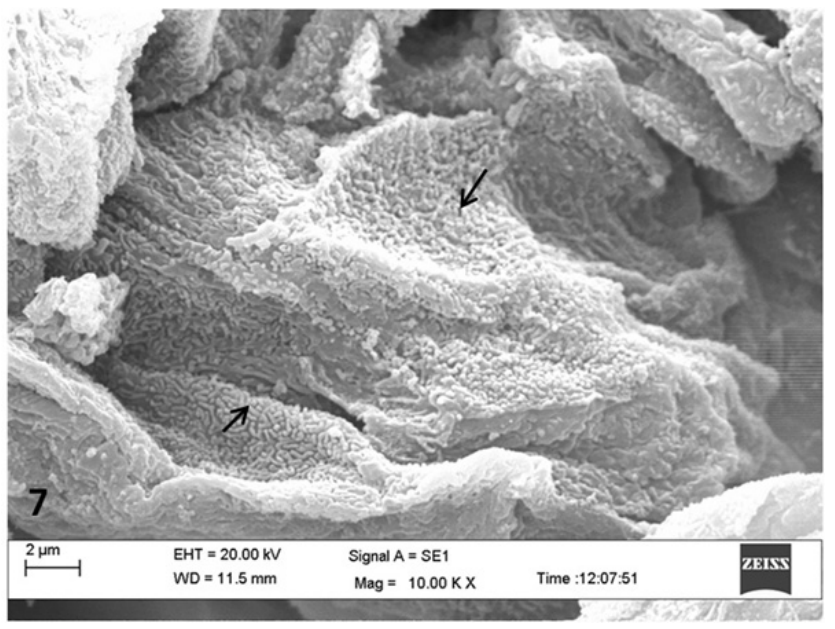

Figure 7: Scanning electron-micrograph at higher magnification showing the inner surface of the crypt presenting the microplicae like bacterial colonies (arrow). $x$ 10000; (bar $2 \mu \mathrm{m}$ ).

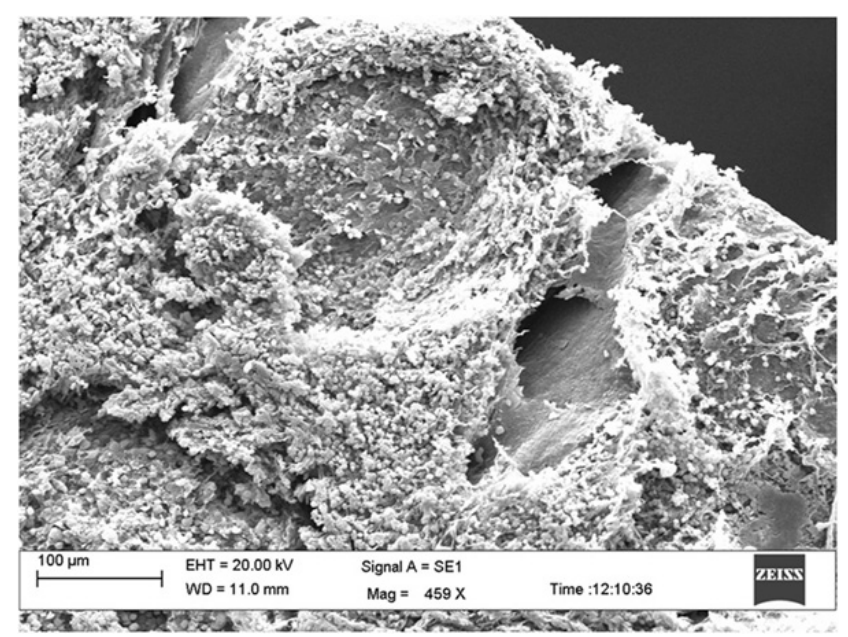

Figure 8: Scanning electron micrograph of the cut surface showing the germinal centre (star), corona (arrow) and parafollicular area. x 459; (bar $100 \mu \mathrm{m})$.

\section{Transmission Electron Microscopy}

The palatine tonsil lined by stratified squamous epithelium demonstrated distinct cell layers. The stratum basale was having cuboidal to columnar shaped cells, and their nuclei were vertically oriented having single nucleolus. The chromatin material was aggregated into smaller clumps towards the nuclear membrane. The electron-plasm of these cells was having different cell organelles, especially the mitochondria, smooth and rough endoplasmic reticulum, few Golgi bodies and electron-dense 
granules throughout the nucleoplasm. The adjacent cells presented small interdigitating villi, which were attached by desmosomes at different places.

The cells of stratum spinosum presented electronlucent nuclei having an irregular surface, some of which presented nuclear indentations. The electrondense chromatin material was localised into smaller clumps. The electron-plasm presented the different cell organelles and the tonofilaments. The intercellular spaces presented the interdigitating villi, which were closely associated with each other (Figure 9). The vertically oriented nuclei close to the stratum basale became horizontal towards the superficial layers. The cells of the stratum granulosum presented larger sized nuclei which were also electron-lucent.

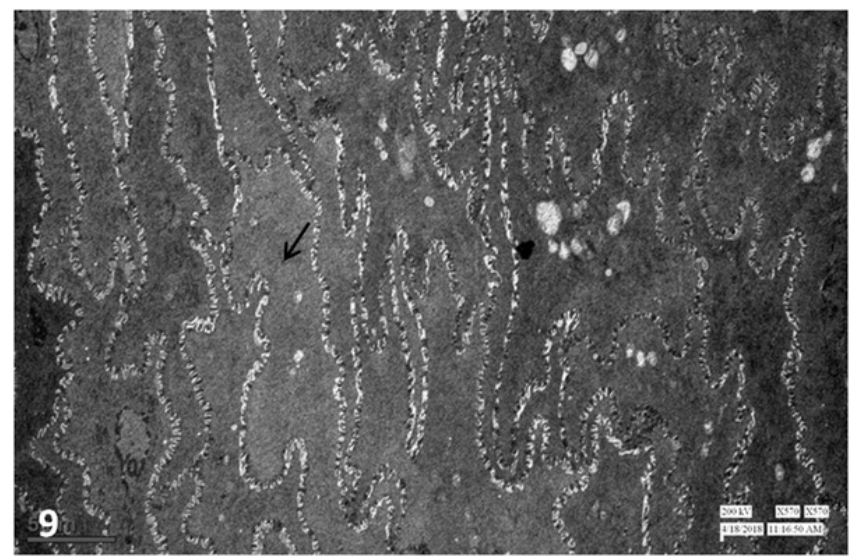

Figure 9: Transmission electron micrograph showing the electron-lucent cells (arrow) of stratum spinosum of keratinised epithelium. x 570; (bar $5 \mu \mathrm{m})$.

The cells of the stratum corneum had long processes and were present in the form of serpentine or interlacing arrangement (Figure 10). Their free surfaces presented the undulating appearance. Only a few of these cells showed the presence of the nuclei, which were smaller and pyknotic in appearance. The majority of the cells were electron-lucent; however, a few electron-dense cells were also interposed between the electron-lucent cells (Figure 10). The intercellular spaces of these cells also presented the interdigitating villi. A few lymphoid cells, especially the lymphocytes, were also observed between the cells at different heights of the epithelium.

The epithelium towards the crypts presented the stratified squamous non-keratinised epithelium having a varying number of rows of nuclei of different strata. The stratum basale at places presented vertically oriented nuclei; whereas at some other places presented horizontally placed nuclei which were

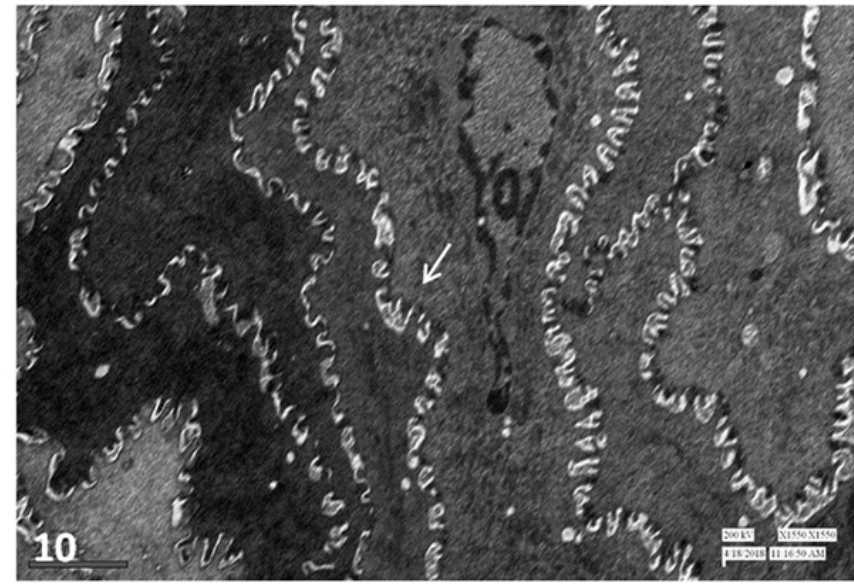

Figure 10: Transmission electron micrograph showing the cells of stratum corneum (arrow) with long processes arranged in a serpentine or interlacing manner. x 1550; (bar 2 $\mu \mathrm{m})$.

electron-lucent in appearance. The features of the different cell layers were more or less similar to those of the outer surface epithelium, except that the stratum superficiale had few cell layers and their nuclei were horizontally placed. The stratified squamous nonkeratinised epithelium further modified into reticular epithelium because of infiltration of underlying lymphoid cells, especially the lymphocytes. The reticular epithelium had indistinct rows of cells, and at places, it was difficult to discern the epithelial and lymphoid cells. The stratum superficiale was drastically reduced in thickness. Its outermost layer presented small microvilli-like structures towards the free surface (Figure 11), which also showed the presence of lymphoid cells, especially the lymphocytes occasionally the granulocytes or macrophages.

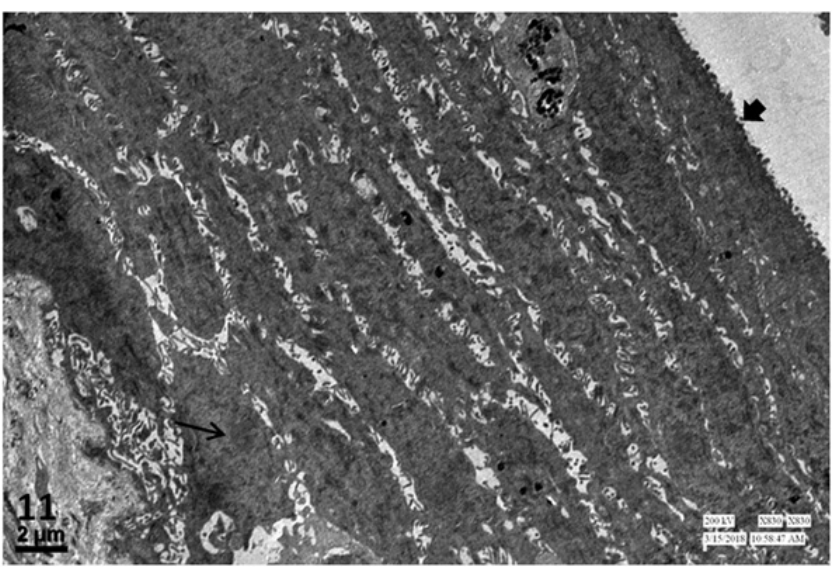

Figure 11: Transmission electron micrograph showing the strata basale (arrow), spinosum and superficiale (arrowhead) of the non-keratinised epithelium. x 830; (bar $2 \mu \mathrm{m})$.

The lamina propria was having clusters of lymphocytes which were of varying shapes and size. 
Most of the lymphocytes had electron-dense chromatin, which was aggregated into smaller clumps. Most of the nuclei had an irregular outer surface. In between the lymphocytes, a few plasma cells were also observed, which presented electron-dense chromatin material arranged in the form of spikes of a cartwheel (Figure 12), and these cells were having more distribution of the endoplasmic reticulum. Besides, in some places, a few macrophages were also observed. In between the clusters of the lymphocytes, a few interdigitating cells, reticular cells and fine blood capillaries were also observed. At some places, a few cells having very large-sized electron-lucent nuclei were also observed near the lymphoid cells. Their nuclei presented a very small concentration of electron-dense chromatin.

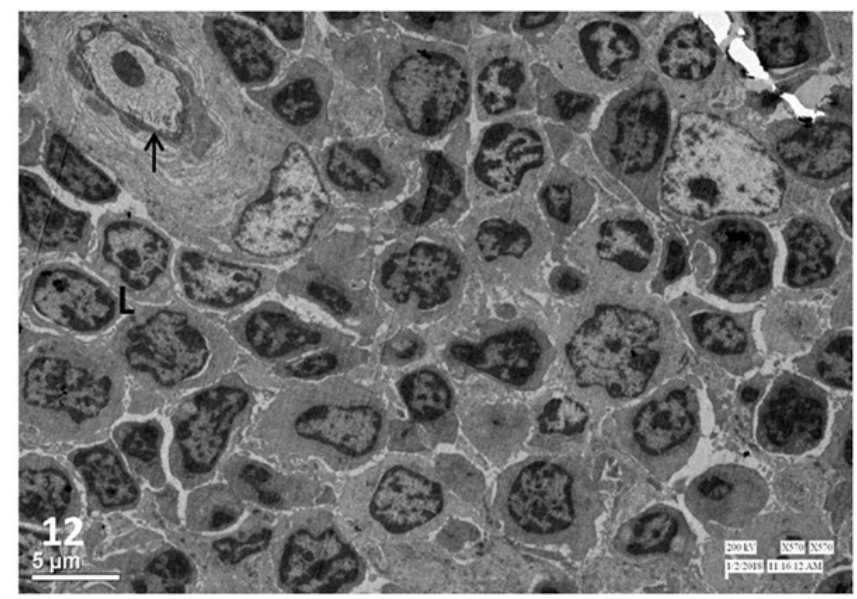

Figure 12: Transmission electron micrograph showing the blood capillary (arrow), lymphocytes (L) and other lymphoid cells. x 570; (bar $5 \mu \mathrm{m})$.

High endothelial venules (HEV's) were observed towards the periphery of the lymphoid tissue or the interfollicular areas. The HEV's had a high cuboidal type of endothelial cells with high cuboidal nuclei, which were irregular in shape (Figures 13, 14). The basal surfaces of these cells were pointed and narrow as compared to those of simple squamous endothelial cells. The endothelial cells had electron-lucent nuclei having a small concentration of electron-dense chromatin material only towards the outer nuclear membrane, and these nuclei contained one centric/eccentric nucleolus. The cytoplasm of these cells contained few mitochondria, smooth and rough endoplasmic reticulum, a few Golgi bodies, multivesicular bodies or membrane-bound bodies and a large number of lysosome-like structures. These cells presented cytoplasmic processes of varying size projecting towards the lumen (Figure 15). These processes presented electron-dense electron-plasm with a few filaments, and at places, some granules, caveolae, and small vesicles like structures arranged in different patterns called vesicular vacuolar organelle (VVOs) (Figures 16-18). The VVO's were observed along with small and large-sized vesicles and vacuoles. However, VVO's were oriented in the form of small clusters arranged in different patterns, and were bounded by membranes and were interconnected with each other. Besides, in some places, a few multivesicular bodies were also observed (Figure 16). A few lymphocytes were observed trafficking in the form of inter-endothelial migration or transvascular migration.

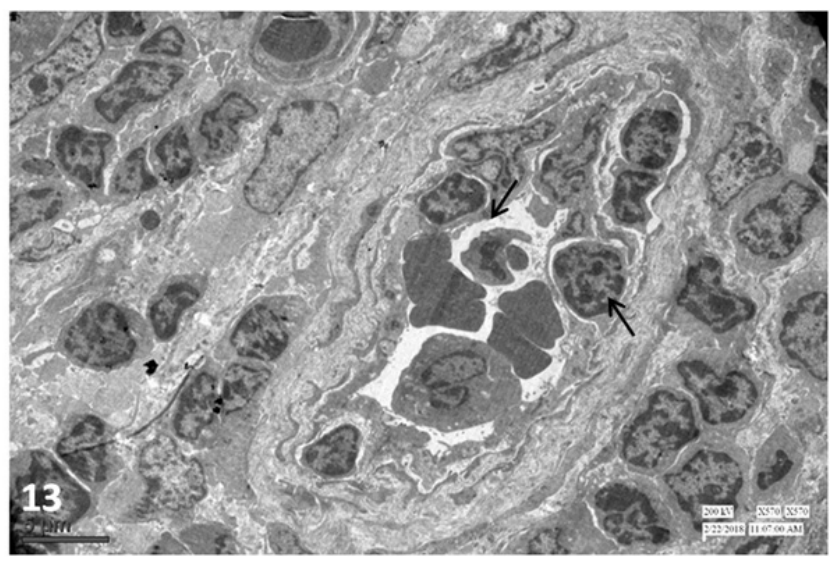

Figure 13: Transmission electron micrograph showing the endothelial cell with lymphocytes (arrow) towards the periphery of the lumen of the high endothelial venule. $x 570$; (bar $5 \mu \mathrm{m}$ ).

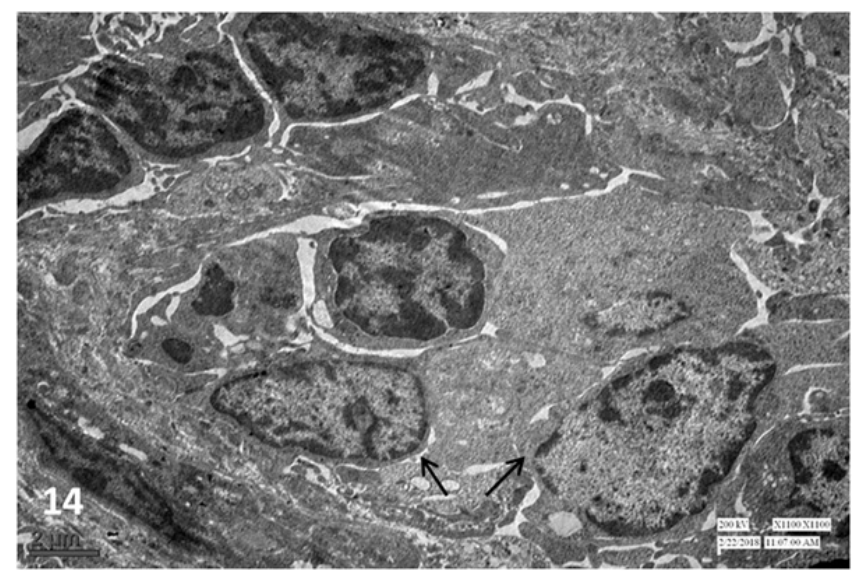

Figure 14: Transmission electron micrograph showing the high endothelial venule (arrow) along with lymphocyte in the propria submucosa. x 1100; (bar $2 \mu \mathrm{m}$ ).

\section{DISCUSSION}

The scanning electron-microscopy revealed folded mucosa comprised of longitudinal folds which further presented transversely oriented grooves and folds as reported in the sheep [13], whereas a large papilla like structure and small elevated area separated from each 


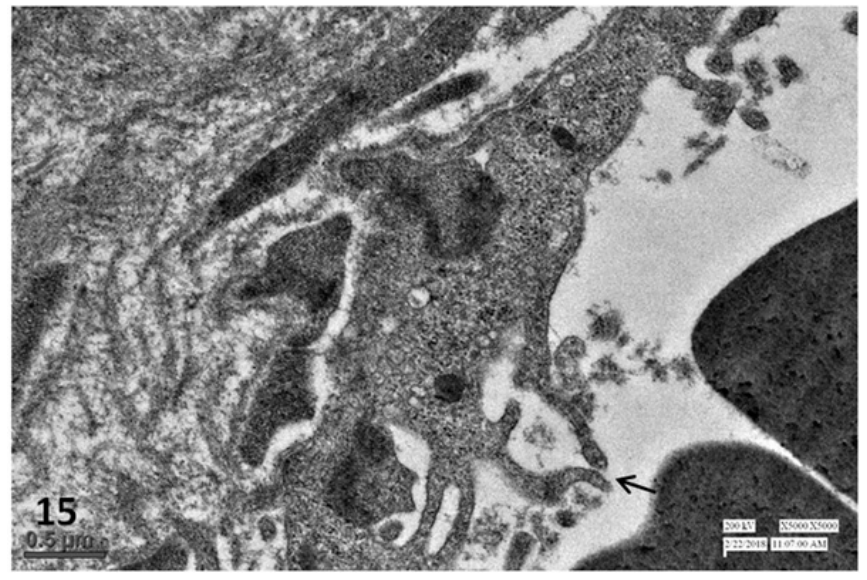

Figure 15: Transmission electron-micrograph at higher magnification showing the cytoplasmic processes (arrow) of the endothelial cell projecting towards the lumen. x 5000; (bar $0.5 \mu \mathrm{m})$.

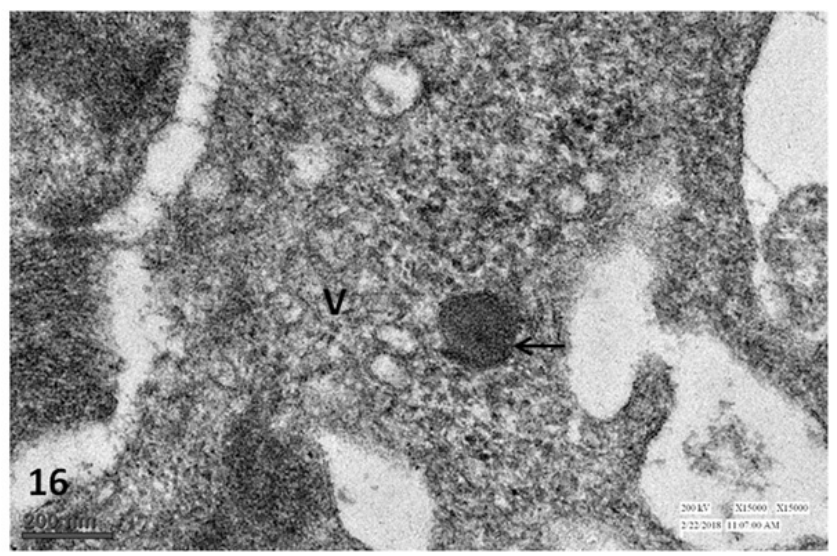

Figure 16: Transmission electron-micrograph at higher magnification showing vesiculo-vacuolar organelle (V) and multivesicular body (arrow). x 15000; (bar $200 \mathrm{~nm}$ ).

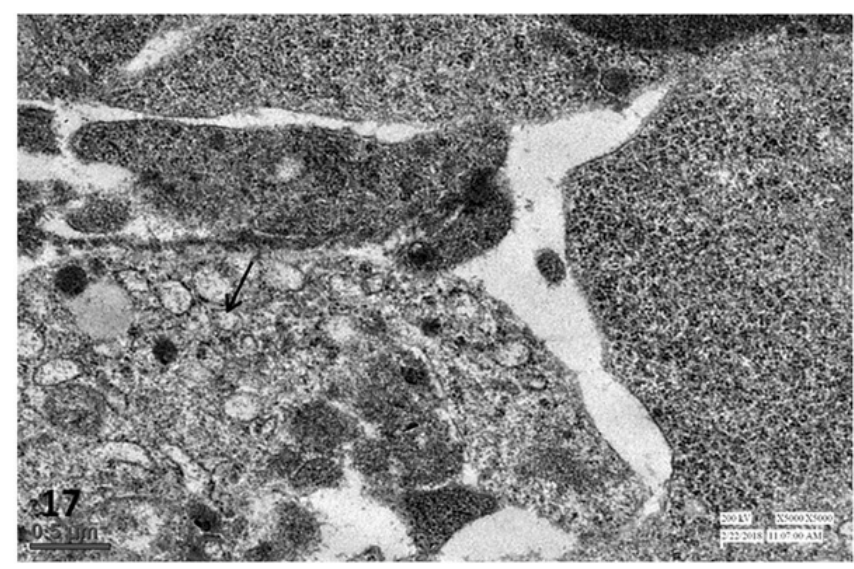

Figure 17: Transmission electron-micrograph showing cytoplasmic processes of the endothelial cell with caveolae (arrow) and vesicles. x 5000; (bar $0.5 \mu \mathrm{m}$ ).

other by linear folds and depression was observed in the goat [14]. These grooves and folds in this study resembled small narrow crest. In the bovine, the epithelial surface was formed mostly by flat angular squamous cells and intermittently round to oval cells

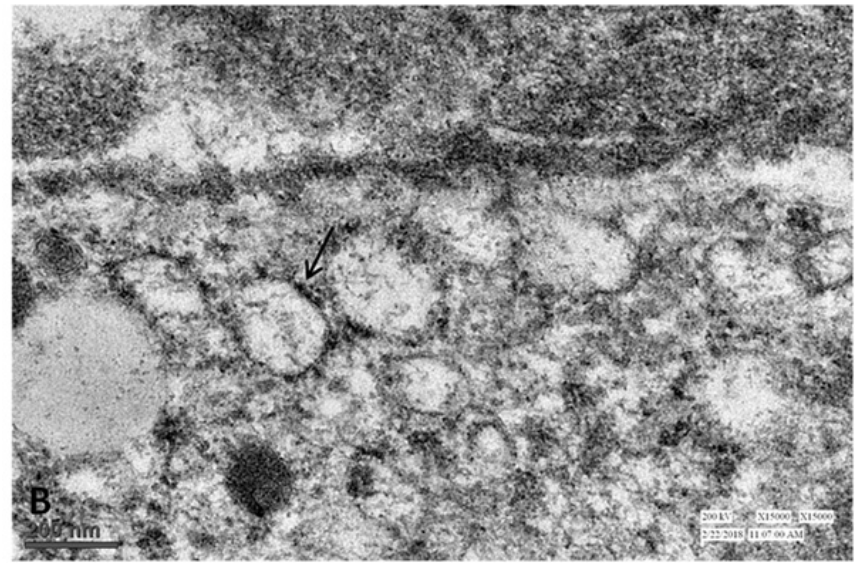

Figure 18: Transmission electron-micrograph at higher magnification showing membrane-bound caveolae (arrow) and vesicles. x 15000; (bar $200 \mathrm{~nm}$ ).

surrounded by closely packed knob-like microvilli [9]. Large-sized distinctly visible crypts with oval or crescent shape openings were observed reported in the sheep [13]. In the horse, the crypts were deep, branched, and extended almost the tonsil's entire depth [15]. The crypts contained desquamating epithelial cells, lymphoid cells and degenerating lymphoid cells along with their debris [13].

Small ducts openings were also observed between the surface cells. These openings had narrow lumenlike structures being obliterated because of the cells' projection or secretion of the glands. In camel, small nodules with irregular luminal surface containing one or two apical openings leading to a crypt and surrounded by circular mucosal ridge were reported [8]. The cut surface in the present study revealed the presence of the lymphoid tissue, especially lymphocytes and the lymphoid follicles as reported in the horse [15]. These follicles presented small fibroblast-like cells and large cells morphologically consistent with antigen-bearing follicular dendritic cells or macrophage in human palatine tonsil [16].

The palatine tonsil was lined by stratified squamous epithelium having stratum basale, spinosum, granulosum and corneum. The cell of the stratum basale revealed vertically oriented nuclei with small clumps of electron-dense chromatin material. The mitochondria, smooth and rough endoplasmic reticulum, few Golgi bodies comprised the different organelles. These were more numerous in the horse, in addition to the large numbers of polyribosomes, and tonofilaments [15]. The cells of stratum spinosum presented electron-lucent nuclei which had irregular surface and dense chromatin in small clumps as described in the horse [15]. The distribution of the 
cellular organelles was similar to that of stratum basale. In the horse, Langerhans cells interspersed between these cells contained large numbers of phagosomes, Golgi bodies, mitochondria, vacuoles, endoplasmic reticulum, and characteristic dumb-bell-shaped Birbeck granules which were formed by langerin, a C-type lectin responsible for the uptake of mannosylated bacterial antigens $[15,17]$. These cells were not observed during the present study. However, these cells, along with monocytes and macrophages, were involved in phagocytosis, processing, and presentation of foreign antigens [18]. The intercellular spaces presented the interdigitating villi, which were closely associated with each other. The ultrastructural features of the cells of stratum granulosum were almost like those of stratum spinosum except the concentration of filaments, which was reduced, and the granules were comparatively more in number. The cells of the stratum corneum possessed long processes and were arranged in a zigzag or serpentine manner. Their nuclei were few and pyknotic in appearance.

The stratum basale of the non-keratinised epithelium had vertical or horizontally placed electronlucent nuclei. The electron-dense basal cells were cuboidal or cylindrical in shape with large oval nuclei in human [19]. It was observed in ovine that the thickness of the epithelium varied from one to more than 10 cell layers [20]. The features of the rest of the cell layers were comparable to those of the outer surface epithelium. The cells on the outermost layer of stratum superficiale presented small microvilli-like arrangement towards the free surface as reported in human [19], horse [15] and ovine [20]. The stratified squamous nonkeratinised epithelium was modified into the reticular epithelium, which was having a further reduced number of rows of different strata. The main characteristic feature was an irregular arrangement of epithelial cells and their close association with infiltrated lymphoid cells. These were often associated with lymphoid cells, especially the lymphocytes and occasionally the granulocytes or macrophages. These may be the precursors of M-cells capable of pinocytosis in the lymphoepithelial tissue [21]. In the ovine, some penetrating electron-dense cytoplasmic processes from cells located underneath the covering squamous were additionally observed with no obvious organelles [20]. The outermost layer of stratum superficiale was intact, and its cells presented small microvilli like arrangement.

The lymphoid parenchyma was comprised the majority of lymphocytes in addition to few plasma cells, macrophages, interdigitating cells, reticular cells, and fine blood capillaries as observed in the horse [15], camel [8] and the Egyptian buffalo [10]. Electron-dense deposits on the plasma membranes of some follicular dendritic cells were identified as immune complexes [22].

The periphery of lymphoid tissue as well as the interfollicular regions presented the specialised high endothelial venules as observed in the horse [15], camel [8] and the Egyptian buffalo [10]. The endothelial cells of the specialised vessels presented the cytoplasmic processes of varying size projecting towards the lumen. These processes presented electron-dense electron-plasm which possessed caveolae and small vesicles distributed either isolated or in small clusters, a few multivesicular bodies, and the VVO's as described earlier in the horse [15], and the camel [8]. A few lymphocytes were observed trafficking through the endothelial wall either in the form of inter-endothelial or transvascular migration. High endothelial venules were the most important structures in the tonsillar interfollicular regions participating in the continuous migration of lymphocytes from the blood to the tonsillar lymphoid tissue [23]. A few peripheral weaker layers of the basal lamina surrounding the HEV provided circumferential compartments for migrating lymphocytes [24]. Expression of vascular adhesion molecules such as VCAM-1, VAP-1, P-selectin, Lselectin played a key role in the adhesion of lymphocytes to endothelial cells of HEVs and their migration from the blood into the tonsil [1].

\section{CONCLUSION}

The SEM revealed mucosal folds of varying shapes, the surface of which presented the squamous arrangement of cells. The higher magnification revealed the microplicae which appeared as filled structures. Distinct crypts and a few glandular ducts openings were observed irregularly on the mucosal surface. TEM demonstrated the different cell organelles of the distinct strata of the surface epithelium, the cellular profiles of propria submucosa as well as lymphocyte migration across the high endothelial venules via the intraendothelial and transendothelial route.

\section{ACKNOWLEDGEMENTS}

The Indian Council for Cultural Relations, ICCR, is kindly acknowledged for international $\mathrm{PhD}$ fellowship to Dr Ibrahim Alhaji Girgiri. The facilities provided by EM Lab., A.I.I.M.S., New Delhi and A.I.R.F., J.N.U., New Delhi are sincerely acknowledged. 


\section{CONFLICT OF INTEREST}

The authors do not have any conflict of interest.

\section{FUNDING STATEMENT}

The funds were not received by any funding agency for the present research work except fellowship to the first author for his Doctoral programme.

\section{REFERENCES}

[1] Perry M, Whyte A. Immunology of the tonsils. Immunol Today 1998; 19: 414-21. https://doi.org/10.1016/S0167-5699(98)01307-3

[2] Brandtzaeg P. Immunology of tonsils and adenoids: everything the ENT surgeon needs to know. Int J Pedia Otorhinolaryngol 2003; 67S1: 69-76. https://doi.org/10.1016/j.ijporl.2003.08.018

[3] Chacker A. Anatomy and microanatomy of tonsils. Ency Immunobiol 2015; 3: 420-26 https://doi.org/10.1016/B978-0-12-374279-7.07005-3

[4] Brandtzaeg P, Kiyono H, Pabst R, Russell MW. Terminology: nomenclature of mucosa-associated lymphoid tissue. Mucosal Immunol 2008; 1: 31-7. https://doi.org/10.1038/mi.2007.9

[5] Kumar P, Timoney JF. Histology and ultrastructure of the equine lingual tonsil. I. Crypt epithelium and associated structures. Anat Histol Embryol 2005; 34: 27-33. https://doi.org/10.1111/j.1439-0264.2004.00560.x

[6] Brandtzaeg P. The mucosal B cell system. Mucosal Immunol 2015; 2: 623-81. https://doi.org/10.1016/B978-0-12-415847-4.00031-8

[7] Kunkel EJ, Butcher EC. Chemokines and the tissue-specific migration of lymphocytes. Immunity $2002 ; 16: 1-4$. https://doi.org/10.1016/S1074-7613(01)00261-8

[8] Zidan M, Pabst R. The microanatomy of the palatine tonsils of the one-humped camel (Camelus dromedarius). Anat Rec 2009; 292: 1129-97.

https://doi.org/10.1002/ar.20948

[9] Palmer MV, Thacker TC, Waters WR. Histology, immunohistochemistry and ultrastructure of the bovine palatine tonsil with special emphasis on the reticular epithelium. Vet Immunol Immunopathol 2009; 127: 277-85. https://doi.org/10.1016/j.vetimm.2008.10.336

[10] Zidan M, Pabst R. The microanatomy of the palatine tonsils of the buffalo (Bos Bubalus). Vet Immunol Immunopathol 2011: 139: 83-9. https://doi.org/10.1016/j.vetimm.2010.08.006

[11] Girgiri IA, Kumar P. Histology, histochemistry and ultrastructure of the nasopharyngeal tonsil of the buffalo (Bubalus bubalis). Anat Histol Embryol 2019; 48: 375-83. https://doi.org/10.1111/ahe.12452
$[12]$

Girgiri IA, Kumar P. Light and electron-microscopic studies on the tubal tonsil of the buffalo (Bubalus bubalis). J Buff Sci 2020; 9: 60-70.

https://doi.org/10.6000/1927-520X.2020.09.08

[13] Kumar P, Singh G, Nagpal SK. Scanning and transmission electron microscopic studies on the palatine tonsil of sheep. Haryana Vet 2009; 48: 33-8.

[14] Kumar P, Kumar P, Kumar S. Light and scanning electron microscopic studies on the palatine tonsil of the goat. Indian J Anim Sci 2006; 76: 1004-06.

[15] Kumar P, Timoney JF. Immunohistochemistry and ultrastructure of the equine palatine tonsil. Anat Histol Embryol 2005; 34: 192-98. https://doi.org/10.1111/j.1439-0264.2005.00594.x

[16] Jović M, Avramović $V$, Vlahović $P$, Savić, V, Veličkov A, Petrović V. Ultrastructure of the human palatine tonsil and its functional significance. Romanian J Morphol Embryol 2015; 56: 371-77.

[17] Valladeau J, Ravel O, Dezutter-Dambuyant C. Langerin, a novel C-type lectin specific to Langerhans cell, is an endocytic receptor that induces the formation of Birbeck granules. Immunity 2000; 12: 71-81. https://doi.org/10.1016/S1074-7613(00)80160-0

[18] Yamamoto Y, Okato S, Takahashi H, Takeda K, Magari S. Distribution and morphology of macrophages in palatine tonsils. Acta Otolaryngol Suppl 1988; 45: 83-95. https://doi.org/10.3109/00016488809125010

[19] Perry ME. The specialised structure of crypt epithelium in the human palatine tonsil and its functional significance. J Anat 1994; 185: 111-27.

[20] Casteleyn C, Cornelissen M, Simoens P, Van Den Broeck W. Ultramicroscopic examination of the ovine tonsillar epithelia. Anat Rec 2010; 293: 879-89. https://doi.org/10.1002/ar.21098

[21] Olah I, Takacs L, Toro I. Formation of lymphoepithelial tissue in the sheep's palatine tonsil. Acta Otolaryngol (Stockh) 1988; 454: 7-17.

https://doi.org/10.3109/00016488809124997

[22] Villanova M, Thielen C, Melot F, Donga J, Eicher S, Heinen $\mathrm{E}$, Antoin $\mathrm{N}$. New histochemical and ultrastructural observations on normal bovine tonsils. Vet Rec 2001; 149: 613-17. https://doi.org/10.1136/vr.149.20.613

[23] Hafeez A, Khan MY, Minhas LA. The relative distribution of high endothelial venules in the subepithelial lymphoid compartments of human palatine tonsil. Ann Pak Inst Med Sci 2008; 4: 223-26.

[24] Sunami-Kataoka $\mathrm{Y}$, Akagi H, Nishizaki K, Taguchi T, Murakami T, Ohtsuka A. Chondroitin sulfate proteoglycan at the basal lamina beneath high endothelial cells in human palatine tonsils: A light and electron microscopic study using the cationic colloidal iron method. Arch Histol Cytol 2001; 64: 535-43.

https://doi.org/10.1679/aohc.64.535

\section{DOI: https://doi.org/10.6000/1927-520X.2021.10.02}

(c) 2021 Girgiri and Kumar; Licensee Lifescience Global.

This is an open access article licensed under the terms of the Creative Commons Attribution Non-Commercial License (http://creativecommons.org/licenses/by-nc/3.0/) which permits unrestricted, non-commercial use, distribution and reproduction in any medium, provided the work is properly cited. 